\title{
Cerebrovasodilatory Contribution of Endogenous Carbon Monoxide During Seizures in Newborn Pigs
}

\author{
MASSROOR POURCYROUS, HENRIETTA S. BADA, HELENA PARFENOVA, \\ MICHAEL L. DALEY, SHELDON B. KORONES, AND CHARLES W. LEFFLER
}

\begin{abstract}
Laboratory for Research in Neonatal Physiology, Departments of Pediatrics [M.P., H.S.B., S.B.K., C.W.L.], Obstetrics and Gynecology [M.P., H.S.B., S.B.K.], and Physiology [H.P., C.W.L., M.P.], The University of Tennessee Health Sciences Center, Memphis, Tennessee 38163, U.S.A.; and Department of Electrical and Computer Engineering, The University of Memphis, Memphis, Tennessee 38152, U.S.A. [M.L.D.]
\end{abstract}

\begin{abstract}
Carbon monoxide $(\mathrm{CO})$ and the excitatory amino acid glutamate both dilate cerebral arterioles in newborn pigs. The key enzyme in $\mathrm{CO}$ synthesis is heme oxygenase, which is highly expressed in neurons with glutamatergic receptor activity as well as cerebral microvessels. During seizures the extracellular level of glutamate is increased, which results in excessive depolarization of neurons. We hypothesized that $\mathrm{CO}$ is a mediator of excitatory amino acid-induced dilation of the cerebral microvasculature during seizures. Three groups of piglets were examined: 1) i.v. normal saline (sham control), 2) topical chromium mesoporphyrin $\left(\mathrm{Cr}-\mathrm{MP}, 15 \times 10^{-6} \mathrm{M}\right)$, and 3) i.v. tin-protoporphyrin (Sn-PP, $4 \mathrm{mg} / \mathrm{kg}$ ). Synthetic metalloporphyrins (Cr-MP and Sn$\mathrm{PP})$ are heme oxygenase inhibitors, thereby reducing $\mathrm{CO}$ synthesis. Implanted closed cranial windows were used to monitor changes in pial arteriolar diameters. Seizures were induced by administration of i.v. bicuculline. Changes in pial arteriolar diameters were monitored during $30 \mathrm{~min}$ of status epilepticus. The percent increase in pial arteriolar dilation in the saline group during seizures was $68 \pm 3 \%$. In the metalloporphyrin groups, the pial arteriolar dilation was markedly reduced $(35 \pm 3 \%$ and $13 \pm 1 \%$, for Cr-MP and Sn-PP, respectively; $p<0.05$, compared with the saline group). We conclude that metalloporphy-
\end{abstract}

\section{ABSTRACT}

rins by inhibition of heme oxygenase and prevention of $\mathrm{CO}$ synthesis attenuate pial arteriolar dilation during seizures. Therefore, $\mathrm{CO}$ appears to be involved in cerebral vasodilation caused by glutamatergic seizures. (Pediatr Res 51: 579-585, 2002)

Abbreviations
aCSF, artificial cerebrospinal fluid
BBB, blood-brain barrier
BP, blood pressure
CBF, cerebral blood flow
CSF, cerebrospinal fluid
CO, carbon monoxide
Cr-MP, chromium mesoporphyrin
GABA, gamma aminobutyric acid
HLL, heme L-lysinate
HO, heme oxygenase
ICP, intracranial pressure
NO, nitric oxide
NOS, nitric oxide synthase
PAD, pial arteriolar diameter
Sn-PP, tin-protoporphyrin

Seizures result when there is an excessive depolarization of neurons within the CNS. One of the mechanisms of excessive depolarization is a relative excess of excitatory versus inhibitory neurotransmitters. Under certain conditions, extracellular levels of glutamate, the principal excitatory neurotransmitter, increase because of high release or diminished reuptake by energy-dependent transport in presynaptic nerve endings and glia. The results are neuronal excitation and seizures (1).

Received July 30, 2001; accepted January 11, 2002.

Correspondence and reprint requests: Massroor Pourcyrous, M.D., Newborn Center, 853 Jefferson Avenue, Memphis, TN 38163, U.S.A.; e-mail: mpourcyrous@utmem.edu
During seizures CBF increases to match neuronal activity and to preserve energy supplies to the brain $(2,3)$. Several mediators could be involved in maintenance of cerebral circulation during seizures. NO, dilator prostanoids, and recently $\mathrm{CO}$ have all been suggested as contributing factors $(3,4)$. Also, systemic hypertension in the absence of BBB integrity and metabolic disturbances such as hypoxia, hypercapnia, and acidosis during seizures may result in cerebral hyperemia (2).

Application of glutamate to the cerebral cortex results in vasodilation of pial arterioles (5). The mechanism of vascular dilation does not appear to involve dilator prostanoids but appears to involve NO through $N$-methyl-D-aspartate receptors 
(6). Also, recently we have shown that glutamate-induced pial arteriolar dilation was significantly reduced by Cr-MP, which is an $\mathrm{HO}$ inhibitor, suggesting a contributory role of $\mathrm{CO}$ in the pial arteriolar dilation caused by the excitatory amino acid (7).

$\mathrm{CO}$ is produced endogenously through heme catabolism by HO (8). The HO-2 system is strongly expressed in the brain (9). Inasmuch as heme does not cross the BBB, it is clear that the function of $\mathrm{HO}$ in the brain does not involve peripheral heme degradation (10). Heme is an essential molecule for life as the prosthetic group of heme-bearing proteins, such as $\mathrm{Hb}$, myoglobin, mitochondrial and microsomal cytochromes, and catalase, peroxidase, and many other enzymes, such as soluble guanylyl cyclase, NOS, and cyclooxygenase. Functional evidence for the potential presence of HO-2 in neurons with glutamatergic expression is suggestive of a special relationship between glutamatergic activity and endogenously produced CO (11). Furthermore, cerebral microvessels have very high expression of HO-2 and produce $\mathrm{CO}(7)$.

We hypothesized that pial arteriolar dilation during seizures is in part mediated via the release of $\mathrm{CO}$. To test this hypothesis, the effects of metalloporphyrins, which are HO inhibitors, on pial arteriolar responses to status epilepticus were investigated in newborn pigs.

\section{METHODS}

The animal protocol was reviewed and approved by the Animal Care and Use Committee of The University of Tennessee Health Science Center. Thirty-four newborn pigs 1-3 d old and $2.0 \pm 0.1 \mathrm{~kg}$ weight were used for this study.

Catheter placement. Piglets were anesthetized with i.m. ketamine hydrochloride and acepromazine, 33 and $3.3 \mathrm{mg} / \mathrm{kg}$, respectively. A catheter was inserted into a femoral vein for injection of $\alpha$-chloralose at an initial dose of $30 \mathrm{mg} / \mathrm{kg}$ followed by $3 \mathrm{mg} / \mathrm{kg}$ every $3 \mathrm{~h}$ to maintain the desired level of anesthesia. This catheter was also used for maintenance infusion of $5 \%$ dextrose water $\left(\mathrm{D}_{5} \mathrm{~W}\right)$ at $4 \mathrm{~mL} / \mathrm{kg}$ per h. Another catheter was inserted into the abdominal aorta via a femoral artery for recording BP and for sampling of blood for $\mathrm{pH}$ and gases. The trachea was intubated, and the lungs were ventilated with room air using a newborn positive-pressure respirator (BP-200). All piglets were paralyzed with pancuronium bromide during seizures. The systemic arterial $\mathrm{BP}, \mathrm{pH}$, and gases were maintained within the normal range during the experiments before seizure induction. Body temperature was maintained between 37 and $38^{\circ} \mathrm{C}$ using a heating pad with a servo-control system.

Electrocortical activity was monitored during seizures using a filtered EEG (cerebral function monitor, model 870; Critikon, Tampa, FL, U.S.A.) (12). Disk electrodes were placed on the scalp over the frontal and biparietal areas. ICP was also recorded using a pressure transducer that was connected to a port of the cranial window that had a direct connection to periarachnoid CSF.

Cranial window placement. Closed cranial windows were implanted over the left parietal cortices for direct measurements of PAD, topical application of different compounds, measurement of ICP, and collection of CSF. To implant the cranial window, the head was immobilized, and the scalp was cut and reflected from the skull. A hole approximately $2 \mathrm{~cm}$ in diameter was made in the skull. An incision was made through the dura and arachnoid membranes, and these membranes were reflected over the edge of the bone. A stainless-steel ring with a premounted glass coverslip was inserted in the hole. The window was cemented in place with dental acrylic. Three needles piercing the ring allowed injection of aCSF under the window, ICP monitoring, and sampling of CSF. The space under the window was filled with aCSF that was equilibrated with $6 \% \mathrm{CO}_{2}$ and $6 \% \mathrm{O}_{2}$, which produced gases and $\mathrm{pH}$ and chemical composition within the normal range for $\mathrm{CSF}[\mathrm{pH}=$ 7.33-7.40, $\mathrm{PCO}_{2}=42-46 \mathrm{~mm} \mathrm{Hg}(5.6-6.13 \mathrm{kPa}), \mathrm{Po}_{2}=$ $43-50 \mathrm{~mm} \mathrm{Hg}(5.73-6.7 \mathrm{kPa}), \mathrm{Na}^{+} 150 \mathrm{mEq} / \mathrm{L}, \mathrm{K}^{+} 3 \mathrm{mEq} / \mathrm{L}$, $\mathrm{Ca}^{2+} 2.5 \mathrm{mEq} / \mathrm{L}, \mathrm{Mg}^{2+} 1.2 \mathrm{mEq} / \mathrm{L}, \mathrm{Cl}^{-} 132 \mathrm{mEq} / \mathrm{L}$, glucose $3.7 \mathrm{mM}$, urea $\left.6 \mathrm{mM}, \mathrm{HCO}_{3}{ }^{-} 25 \mathrm{mEq} / \mathrm{L}\right]$. The volume directly below the window was approximately $500 \mu \mathrm{L}$ and was contiguous with the periarachnoid space.

Pial arterioles were observed with a dissecting microscope. PADs were measured using a television camera mounted on the microscope, a video monitor, and a video micrometer (Model VPA-1000, FOR-A, Los Angeles, CA, U.S.A.). Pial arterioles of different sizes $(<100 \mu \mathrm{m}$ in diameters) were selected and monitored in each piglet. Briefly, the images of arterioles were displayed on the television monitor, and the sides of each vessel were bracketed by parallel lines projected by the micrometer. As the arteriolar diameter changed, the lines were moved manually to correspond with the vessel walls. Precalibration of the distance between the lines allowed determination of arteriolar diameters. After implantation of the window, a 30-min stabilization period was allowed before experimentation.

Materials. The HO substrate, HLL, was used to determine an appropriate i.v. dosage of Sn-PP. HLL was prepared using methods described by Tenhunen et al. (13). It was protected from light at all times until placement beneath the cranial window, and the cranial window was only illuminated during vessel diameter measurements. HLL was stored at $-30^{\circ} \mathrm{C}$. HLL was diluted in aCSF $\left(10^{-7} \mathrm{M}\right)$ for placement under the cranial window. The HO inhibitors, Sn-PP and Cr-MP, were purchased from Porphyrin Products Inc. (Logan, UT, U.S.A.). Metalloporphyrins (Sn-PP and Cr-MP) were similarly protected from light. Among the metalloporphyrins, Sn-PP when systemically injected will cross the BBB. Sn-PP has a 3.4-h half-life in plasma and a significant concentration in brain 1-4 $\mathrm{h}$ after its injection $(14,15)$. Sn-PP has a marked inhibitory effect on cerebral HO activity (16).

Pancuronium bromide was purchased from Astra Pharmaceutical Products Inc. (Westborough, MA, U.S.A.). Bicuculline, isoproterenol, and sodium nitroprusside were purchased from Sigma Chemical Co. (St. Louis, MO, U.S.A.).

Experimental procedures. Because an i.v. dose for Sn-PP has not been established in newborn pigs, first in a separate group of piglets $(n=13)$ we examined dosage for i.v. Sn-PP. A dose range of 2 to $5 \mathrm{mg} / \mathrm{kg}$ of Sn-PP was tried. Pial arteriolar responses to topical cerebral cortical application of HLL $\left(10^{-7}\right.$ M) were evaluated before and after i.v. administration of normal saline or Sn-PP. Pial arteriolar dilation is an expected 
response to HLL; this response is caused by heme degradation, releasing $\mathrm{CO}$ (7). This vasodilation is expected to be prevented by HO inhibition with Sn-PP. Furthermore, with an optimal dose of Sn-PP, pial arteriolar responses to topical isoproterenol $\left(10^{-6} \mathrm{M}\right)$ should be preserved. As to Cr-MP, we have previously shown that topical application of Cr-MP at $15 \times 10^{-6} \mathrm{M}$ is an appropriate dose for inhibition of $\mathrm{HO}$ activity (7).

In the second part of the study, the contributory role of $\mathrm{CO}$ in cerebrovascular dilation during seizures was investigated ( $n$ $=21$ ). Three groups of newborn pigs were studied: sham control group that received normal saline at $4 \mathrm{~mL} / \mathrm{kg}$, i.v. $(n=$ 7), Sn-PP group ( $4 \mathrm{mg} / \mathrm{kg}$, i.v.; $n=9)$, and Cr-MP group (topical cerebral application of $15 \times 10^{-6} \mathrm{M} ; n=5$ ).

Before induction of seizures, to confirm that metalloporphyrins were not nonspecifically altering pial arteriolar responses, responses to topical application of isoproterenol $\left(10^{-6} \mathrm{M}\right)$ and sodium nitroprusside $\left(10^{-6} \mathrm{M}\right)$ were evaluated separately in a consecutive manner before and after the treatment with i.v. Sn-PP, topical application of Cr-MP, or i.v. normal saline (sham control). A $10^{-6} \mathrm{M}$ concentration is considered a middle dose for vasodilatory responses to isoproterenol and sodium nitroprusside. At this concentration responses are reversible in a reasonable time period. Seizures were induced by i.v. injection of $3 \mathrm{mg} / \mathrm{kg}$ bicuculline. Bicuculline is a $\gamma$-aminobutyric acid inhibitor; $\gamma$-aminobutyric acid is an inhibitory neurotransmitter, inhibition of which causes glutamatergic seizures.

Cyclic nucleotide analysis. Cortical periarachnoid CSF (0.4 $\mathrm{mL}$ ) collected from under the cranial window was mixed with EDTA $(5 \mu \mathrm{L})$ and stored at $-60^{\circ} \mathrm{C}$ until assayed. Multiple CSF samples were collected during different interventions. Cyclic AMP and cGMP were measured by RIA (17).

Statistical analysis. Values for each variable are presented as mean \pm SEM. Comparisons within and between populations within each experimental group used ANOVA with repeated measures. Fisher's protected least significant difference test was used to determine differences between populations within each group. A $p<0.05$ was considered significant.

\section{RESULTS}

The selected baseline PADs ranged from 40 to $96 \mu \mathrm{m}$ at the onset of the study.

In the first part of the study, Sn-PP at $2 \mathrm{mg} / \mathrm{kg}$ caused a partial attenuation of pial arteriolar dilation that was induced by HLL. However, Sn-PP at 3 to $4 \mathrm{mg} / \mathrm{kg}$ was deemed to be an appropriate dose as vasodilatory responses to HLL were significantly attenuated (Fig. 1) without any reduction in isoproterenol-induced arteriolar dilation. Cerebrovascular responses to isoproterenol, obtained after administration of $5 \mathrm{mg} / \mathrm{kg}$ Sn-PP, varied from no response, to minimal vasodilation, to vasoconstriction. Furthermore, $5 \mathrm{mg} / \mathrm{kg}$ Sn-PP usually caused cardiovascular instability. It is unclear whether Sn-PP at 5 $\mathrm{mg} / \mathrm{kg}$ injures cerebral microvessels or reduces cerebral vascular responses by another effect, possibly by compromising cardiovascular control. It is clear that $5 \mathrm{mg} / \mathrm{kg}$ is too much.

In the second part of the study, before the induction of seizures, cerebrovascular reactivity to isoproterenol at $10^{-6} \mathrm{M}$ and sodium nitroprusside at $10^{-6} \mathrm{M}$ was evaluated before and

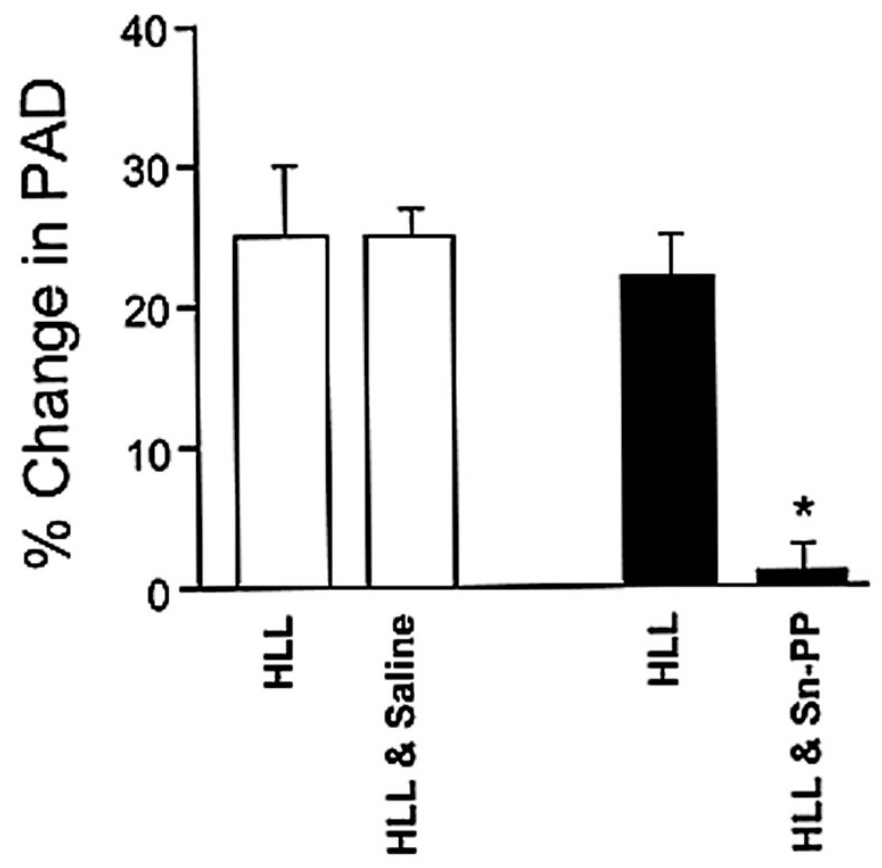

Figure 1. Effects of i.v. saline or Sn-PP $(4 \mathrm{mg} / \mathrm{kg})$ on PAD of newborn pigs that already received topical HLL $\left(10^{-7} \mathrm{M}\right) n=4$ newborn pigs. Values are mean \pm SEM. $* p<0.05$ HLL plus Sn-PP compared with HLL alone.

after the administration of Sn-PP, Cr-MP, and saline. Pial arteriolar dilations in response to these vasogenic stimuli were not significantly different within these three groups (Fig. 2).

The arterial $\mathrm{pH}$ and gases, BP, and temperature were kept within the normal range until the seizure induction. During seizures, BP, HR, and ICP increased significantly, which coincided with abnormal electrocortical activity. Also, $\mathrm{PaCO}_{2}$ increased and $\mathrm{PaO}_{2}$ decreased during status epilepticus. The percent change in arterial blood gases, vital signs, and ICP were similar in saline- and metalloporphyrin-treated groups during status epilepticus (Fig. 3).

Before induction of seizures, administration of metalloporphyrins caused a transient pial arteriolar dilation $(10 \pm 2 \%)$ that was followed by vasoconstriction $(10 \pm 1 \%)$. During status epilepticus, pial arteriolar dilation did occur in the saline- and metalloporphyrin-treated groups. However, this dilation was markedly attenuated in the metalloporphyrintreated groups when compared with the saline-treated group (Fig. 4).

Periarachnoid CSF cyclic nucleotides (cGMP and cAMP) were measured during different interventions in the metalloporphyrin- and saline-treated groups. Before seizure induction, metalloporphyrins caused increased cortical CSF cGMP and cAMP $(p<0.05)$. During status epilepticus, cyclic nucleotides rose markedly in all three groups (Fig. 5). The rises in both cGMP and cAMP were more pronounced in the metalloporphyrin-treated groups compared with the saline-treated group (2- to 3-fold versus 4- to 6-fold).

\section{DISCUSSION}

In this study, pial arteriolar dilation secondary to seizures was significantly attenuated in the metalloporphyrin (HO in- 

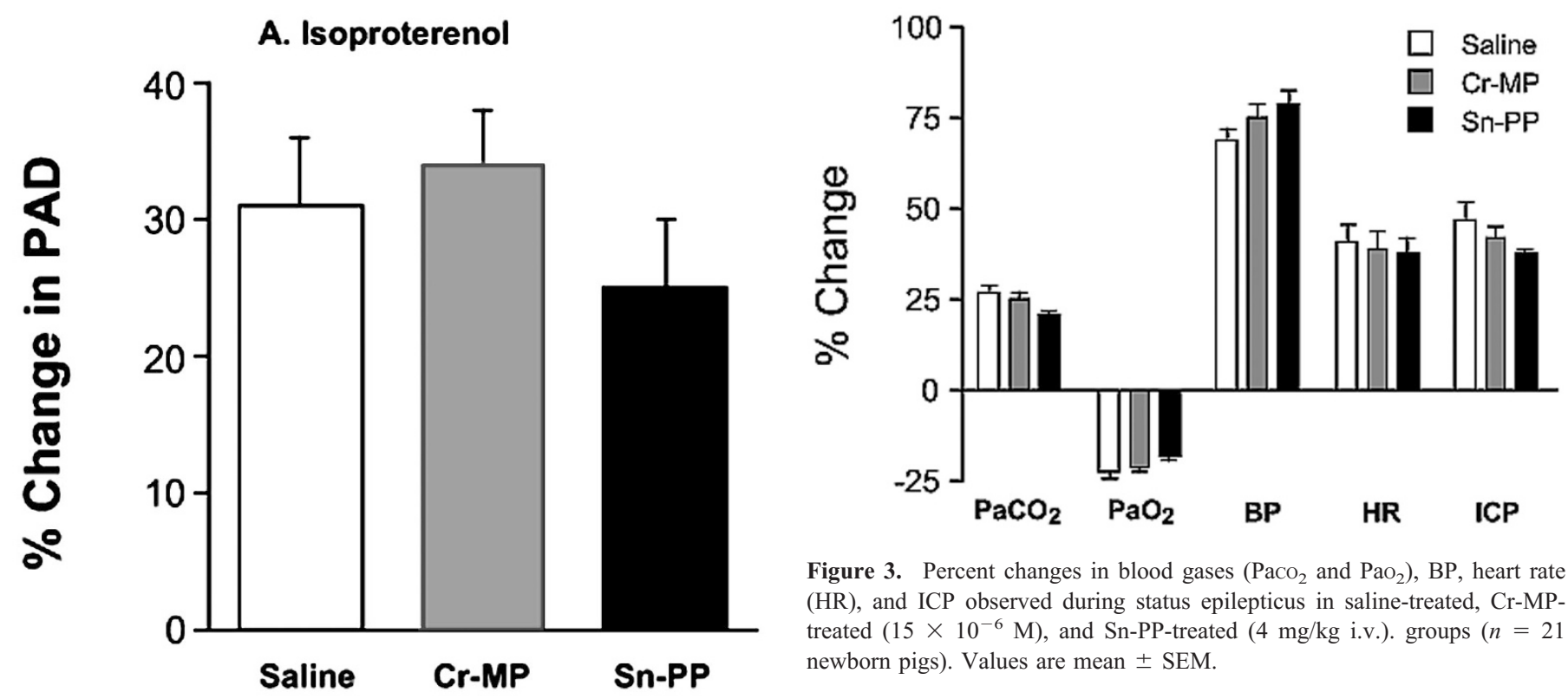

Figure 3. Percent changes in blood gases $\left(\mathrm{PaCO}_{2}\right.$ and $\left.\mathrm{PaO}_{2}\right), \mathrm{BP}$, heart rate (HR), and ICP observed during status epilepticus in saline-treated, Cr-MPtreated $\left(15 \times 10^{-6} \mathrm{M}\right)$, and Sn-PP-treated $(4 \mathrm{mg} / \mathrm{kg}$ i.v. $)$. groups $(n=21$ newborn pigs). Values are mean \pm SEM.

B. Na-nitroprusside

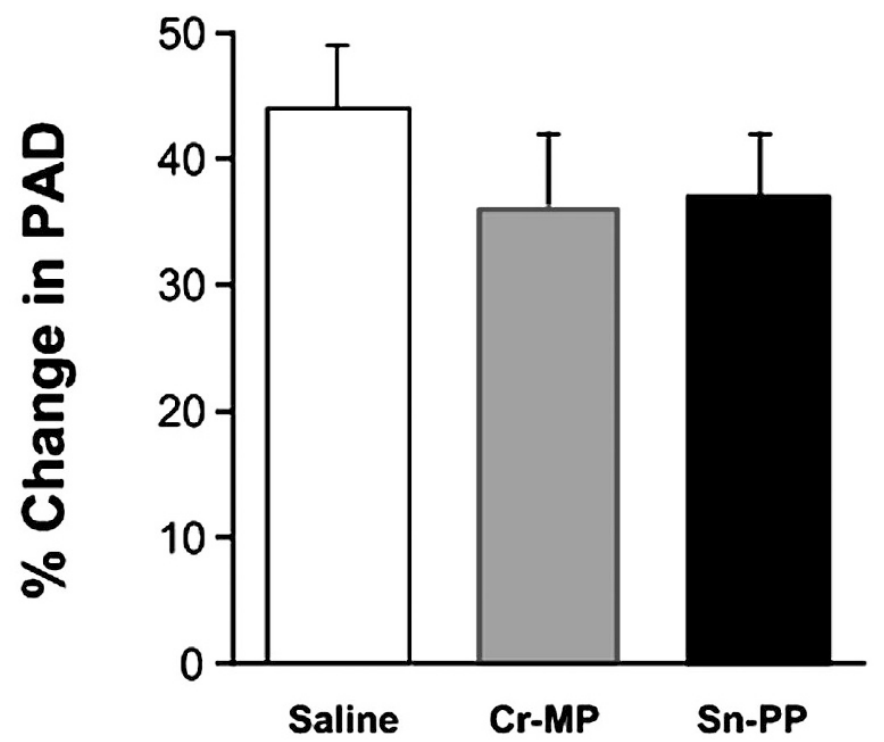

Figure 2. Effects of topically applied isoproterenol $\left(10^{-6} \mathrm{M} ; A\right)$, and sodium nitroprusside $\left(10^{-6} \mathrm{M} ; B\right)$, on PAD of newborn pigs after administration of saline, Cr-MP $\left(15 \times 10^{-6} \mathrm{M}\right)$, or Sn-PP $(4 \mathrm{mg} / \mathrm{kg}$ i.v. $) n=13$ newborn pigs. Values are mean \pm SEM.

hibitor) -treated groups when compared with saline-treated newborn pigs. Both endogenously produced and exogenously administered $\mathrm{CO}$ are potent dilators of cerebral arterioles in newborn pigs (7). Our findings are in contrast to those obtained from adult rabbit and dog basilar and middle cerebral arteries in vitro (18). Therefore, $\mathrm{CO}$ may elicit less vasodilatory response in large cerebral arteries, in adults, or in other species (18). Because the previous studies were in isolated arteries, the



Figure 4. Percent changes in $\mathrm{PAD}$ that occurred during status epilepticus in saline-treated, Cr-MP-treated $\left(15 \times 10^{-6} \mathrm{M}\right)$, and Sn-PP-treated $(4 \mathrm{mg} / \mathrm{kg}$ i.v. $)$ groups. ( $n=21$ newborn pigs). ${ }^{*} p<0.05$ compared with saline; $+p<0.05$ compared with Cr-MP. Values are mean \pm SEM.

results are difficult to compare with the present ones on arterioles in vivo.

Endogenous $\mathrm{CO}$ is produced by heme destruction catalyzed by HO (19). In the brain, HO-1, the inducible form, and HO-2, a constitutive form, are both present in microvascular endothelial and smooth muscle cells $(7,20,21)$. Under normal conditions, HO-1 is present in selected neurons; under stress it can be induced rapidly (22). Also, HO-2 in the brain is abundant in neurons of autonomic ganglia and also in the discrete neuronal population with glutamatergic expression $(20,23)$. Glutamate receptors are also expressed in cultured cerebrovascular endothelial cells (24). Seemingly, HO and glutamate receptors have similar localization in the brain. Glutamate has been reported 

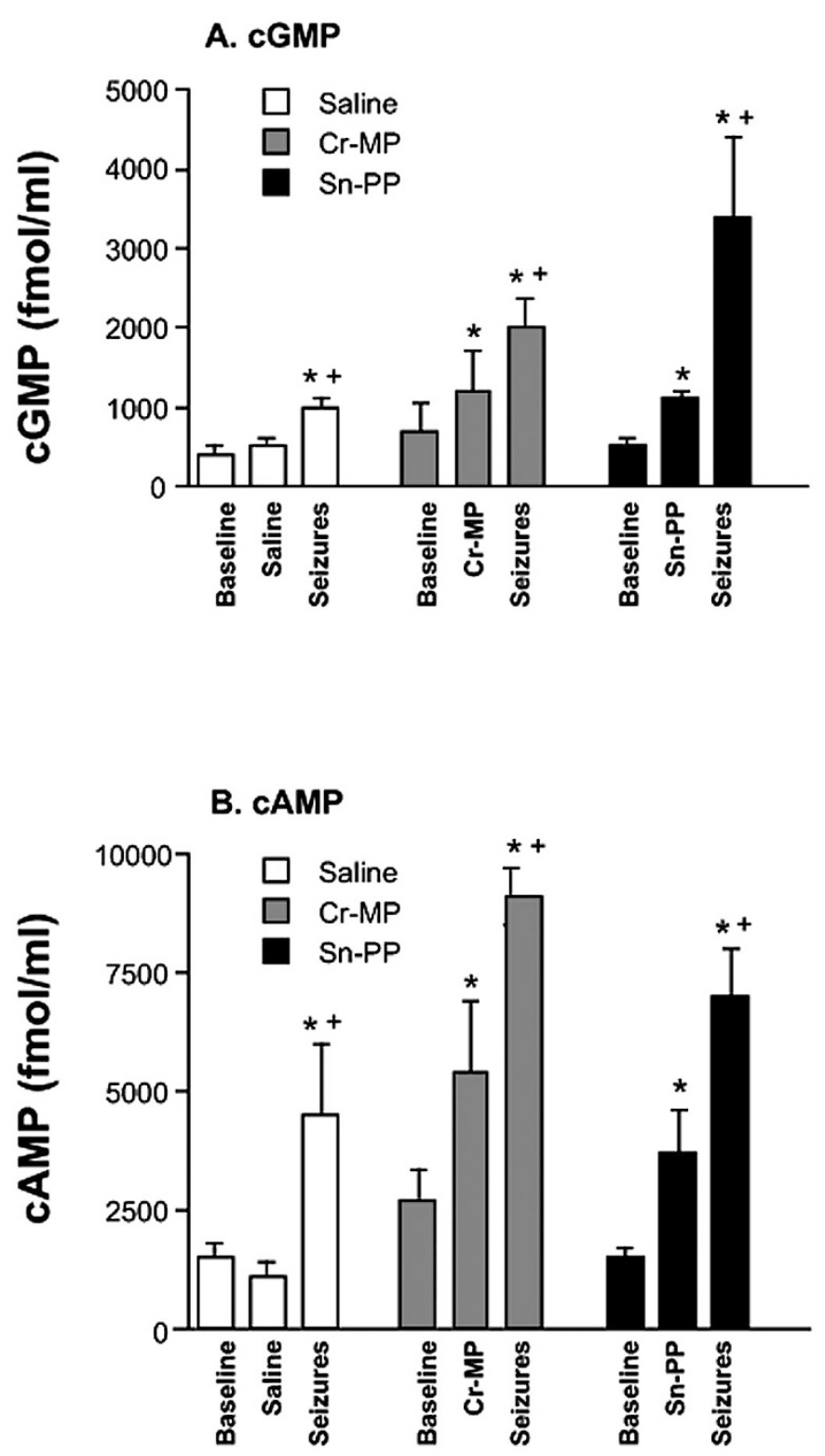

Fig. 5. Changes in CSF cGMP $(A)$ and cAMP $(B)$ levels during baseline; after treatment with saline, Cr-MP $\left(15 \times 10^{-6} \mathrm{M}\right)$, or Sn-PP $(4 \mathrm{mg} / \mathrm{kg}$ i.v. $)$; and during seizures. ( $n=21$ newborn pigs). ${ }^{*} p<0.05$ compared with baseline in each group; $+p<0.05$ for seizures compared with treatment in each group. Values are mean \pm SEM.

to regulate $\mathrm{CO}$ release through metabotropic receptors, possibly through an action on protein kinase $\mathrm{C}$ and stimulation of HO-2 synthesis (25).

Our findings that metalloporphyrins resulted in transient dilation of pial arterioles was surprising at first, as inhibition of endogenous $\mathrm{CO}$ production is expected to bring about vasoconstriction rather than vasodilation. This dilation appears to involve NO, because Cr-MP-induced dilation was abolished by pretreatment with $N^{\omega}$-nitro-L-arginine which is a NOS inhibitor (7). Pertinent to this point, metalloporphyrins have previously been shown to be capable of NOS activation (26). Also, by inhibiting endogenous $\mathrm{CO}$ production, metalloporphyrins may remove tonic inhibition of NOS by $\mathrm{CO}$ binding to the NOS heme (27). The possibility that the heme-HO-CO system of cerebral arterial vessels is bifunctional, with endogenous $\mathrm{CO}$ being capable of subserving dilatory mechanisms via its action on vascular smooth muscle and vasoconstrictor mechanisms via inhibitory actions on the NOS-NO system of the endothelium, must also be considered.

Pial arteriolar dilation and increased $\mathrm{CBF}$ occur during seizures (2-4). In the present study both topical and systemically administered metalloporphyrins caused a significant attenuation of pial arteriolar dilation during status epilepticus, which we believe is caused by the inhibition of $\mathrm{CO}$ production. In rats, similar to piglets, the vasodilatory effects of heme on resistance vessels were promptly reversed by inhibitors of $\mathrm{HO}$ $(7,28)$. HO catabolizes heme to $\mathrm{CO}$, free iron, and biliverdin. The vasodilatory manifestations in rats were not mimicked by biliverdin or attenuated by iron chelators but could be mimicked by exogenous CO (28). Therefore, seizure-induced vasodilation was most likely caused by the formation of $\mathrm{CO}$, as HO inhibitors attenuated the vasodilation. HO-2-containing nerve fibers in the adventitial layer of pial vessels are one potential source of $\mathrm{CO}$ during seizures (20). Another potential source of $\mathrm{CO}$ during seizures is the glutamatergic neuronal hyperactivity, which results in stimulation of HO-2 synthesis (25). Also, much $\mathrm{CO}$ is produced in cerebral microvessels; namely, in endothelial and smooth muscle cells $(7,20)$.

During status epilepticus, pial arteriolar dilation was significantly attenuated in the metalloporphyrin groups, but it was not totally abolished. The partial pial arteriolar dilation during status epilepticus in the metalloporphyrin group can be explained by the influence of other mediators, such as NO or prostanoids, which may have provided a compensatory dilatory role. There is a similarity among cellular localization of HO, NOS, and prostaglandin cyclooxygenase with a potential for coordinated and complementary dilatory function (20). Montecot et al. (4) observed a significant reduction in cerebral hyperemia during seizures when rats were pretreated with Sn-PP; however, Sn-PP did not affect the cerebrovascular responses to hypercapnia. This finding can be explained by prostanoid-dependent mechanisms in hypercapnia-induced vasodilation, which is independent of CO production. Our previous study also indicated that metalloporphyrins had no effect on hypercapnia-induced vasodilation (7). These current findings suggest that $\mathrm{CO}$ participates in the regulation of $\mathrm{CBF}$ that is associated specifically with glutamate release.

$\mathrm{CO}$ can be an endothelially derived relaxing factor similar to prostanoids and NO (20). During seizures, the capacity of the cerebral tissue to generate $\mathrm{CO}$ is overwhelmingly higher than that of $\mathrm{NO}(8)$. Both $\mathrm{NO}$ and $\mathrm{CO}$ can exert their vasodilatory action by activation of soluble guanylyl cyclase, but $\mathrm{CO}$ can act predominantly by increasing the outward $\mathrm{K}^{+}$currents through Ca-activated $\mathrm{K}^{+}$channels in vascular smooth muscle cells (29). Furthermore, in our preliminary study, we have reported recently that in newborn pigs, Ca-activated $\mathrm{K}^{+}$channels in cerebral artery smooth muscle cells are sites of action for $\mathrm{CO}(30)$.

$\mathrm{CO}$ can affect BP through CNS-mediated influences on vascular tone in chronically hypertensive subjects (31). These influences are likely related to local interaction between HO and glutamatergic transmission in the nucleus tractus solitarius 
in the medulla oblongata $(32,33)$. In our piglets, metalloporphyrins at the doses used had no influence on BP because the hypertension was not chronic but rather acutely induced by seizures.

CSF cyclic nucleotides were evaluated in our study. As one of the mechanisms for CO-induced vasodilation could be via activation of soluble guanylyl cyclase and production of cGMP, we did not discount the possibility of an attenuated level of cGMP after metalloporphyrin administration. However, we observed a significant rise in cGMP level independent of $\mathrm{CO}$ production. Other studies have shown that exogenous $\mathrm{CO}$ does not increase cerebral cGMP in piglets or rats $(7,34)$. Furthermore, we found that Cr-MP causes an acute dilation that involves NO $(7,26)$, which could account for the elevation of cGMP. As noted above (7), CO-induced dilation of cerebral microvessels does not appear to relate to $\mathrm{CO}$ activation of guanylyl cyclase but instead to Ca-activated $\mathrm{K}^{+}$channels.

cAMP also rose significantly in the metalloporphyrin groups. In our previous study, we found that cAMP production with exogenous $\mathrm{CO}$ administration was mildly elevated; the level was quantitatively insignificant when compared with cAMP produced by isoproterenol or iloprost (7).

cAMP and cGMP increased significantly during seizures regardless of whether the treatment was saline or metalloporphyrins. That brain cyclic nucleotides are increased during seizures has been reported, and appropriate treatment with anticonvulsants will modify the brain cyclic nucleotides (35). The greater rise in cyclic nucleotides in the metalloporphyrintreated groups compared with the saline-treated group may be explained by a compensatory increase of $\mathrm{NO}$ and prostanoids (30), as CO production was inhibited by Sn-PP and Cr-MP in our experimental animals. cAMP and cGMP production are known to be stimulated by prostanoids and NO, respectively (17).

The heme-HO-CO system in the brain may be protective against neuronal cell death (36). In experiments using transgenic mice, HO-1-overexpressing neurons were found to be protected against chemical stimuli that were neurotoxic, such as glutamate (37). When HO activity was inhibited, protection against glutamate was lost (37). Heme degradation catalyzed by $\mathrm{HO}$ results not only in the production of $\mathrm{CO}$ but also of free iron and biliverdin. The protective role of the heme-HO-CO system could be related as well to release of other byproducts of heme degradation such as biliverdin or bilirubin. Bilirubin is a strong antioxidant. Considering the relative deficiency in glutathione and ascorbic acid of neuronal tissues, particularly in neonates, the antioxidant activity of bilirubin, which is released as a result of heme breakdown during seizures, may also be important for brain protection (38).

\section{CONCLUSION}

We conclude that in newborn pigs, HO inhibitors attenuate seizure-induced cerebral vasodilation. We propose that $\mathrm{CO}$ is involved in the cerebral vasodilation caused by seizures from excessive glutamatergic stimulation.
Acknowledgments. The authors thank Alex Fedinec for excellent technical assistance, Rosalind Griffin for editorial assistance, and R.A. Johnson (Tulane University) for preparing and giving us HLL.

\section{REFERENCES}

1. Volpe JJ 1995 Neonatal seizures. In: Neurology of the Newborn, 3rd Ed. WB Saunders, Philadelphia, pp172-173

2. Pourcyrous M, Leffler CW, Bada HS, Korones SB, Stidham GL, Busija DW 1992 Effects of pancuronium bromide on cerebral blood flow changes during seizures in newborn pigs. Pediatr Res 3:636-639

3. Busija DW, Leffler CW 1989 Role of prostanoids in cerebrovascular responses during seizures in piglets. Am J Physiol 256:H120-H125

4. Montecot C, Seylaz J, Pinard E 1998 Carbon monoxide regulates cerebral blood flow in epileptic seizures but not in hypercapnia. Neuroreport 10:2341-2346

5. Busija DW, Leffler CW 1989 Dilator effects of amino acid neurotransmitters on piglet pial arterioles. Am J Physiol 257:H1200-H1203

6. Meng W, Tobin JR, Busija DW 1995 Glutamate-induced cerebral vasodilation is mediated by nitric oxide through $N$-methyl-D-aspartate receptors. Stroke 26:857-862

7. Leffler CW, Nasjletti A, Yu C, Johnson RA, Fedinec AL, Walker N 1999 Carbon monoxide and cerebral microvascular tone in newborn pigs. Am J Physiol 276:H1641-H1646

8. Maines MD 1997 The heme oxygenase system: a regulator of second messenger gases. Annu Rev Pharmacol Toxicol 37:517-554

9. Sun Y, Rotenberg MO, Maines MD 1990 Developmental expression of heme oxygenase isozymes in rat brain: two HO-2 mRNAs are detected. J Biol Chem 265:8212-8217

10. Linden IB, Tokola O, Karlsson M, Tenhunen R 1987 Fate of heme after parenteral administration of heme arginate to rabbits. J Pharm Pharmacol 39:96-102

11. Silva CC, Almeida VA, Haibara AS, Johnson RA, Colombari E 1999 Role of carbon monoxide in L-glutamate-induced cardiovascular responses in nucleus tractus solitarius of conscious rats. Brain Res 824:147-152

12. Stidham GL, Nugent SK, Rogers MC 1980 Monitoring cerebral electrical function in the ICU. Crit Care Med 8:519-523

13. Tenhunen R, Tokola O, Linden IB 1987 A new stable haem compound. J Pharm Pharmacol 39:780-786

14. Kappas A, Drummond GS, Manola T, Petmezaki S, Valaes T 1988 Sn-Protoporphyrin use in the management of hyperbilirubinemia in term newborns with direct Coombspositive ABO incompatibility. Pediatrics 81:485-497

15. Anderson KE, Simionatto CS, Drummond GS, Kappas A 1984 Tissue distribution and disposition of tin-protoporphyrin, a potent competitive inhibitor of heme oxygenase. J Pharmacol Exp Ther 228:327-333

16. Mark JA, Maines MD 1992 Tin-protoporphyrin-mediated disruption in vivo of heme oxygenase- 2 protein integrity and activity in rat brain. Pediatr Res 32:324-329

17. Pourcyrous M, Parfenova H, Bada HS, Korones SB, Leffler CW 1997 Changes in cerebral cyclic nucleotides and cerebral blood flow during prolonged asphyxia and recovery in newborn pigs. Pediatr Res 41:617-623

18. Brian Jr JE, Heistad DD, Faraci FM 1994 Effect of carbon monoxide on rabbit cerebral arteries. Stroke 25:639-644

19. Maines MD 1997 The heme oxygenase system and its functions in the brain. Cell Mol Biol 46:573-585

20. Zakhary R, Gaine SP, Dinerman JL, Ruat M, Flavahan NA, Snyder SH 1996 Heme oxygenase-2: endothelial and neuronal localization and role in endotheliumdependent relaxation. Proc Natl Acad Sci USA 93:795-798

21. Christodoulides N, Durante W, Kroll MH, Schafer AI 1995 Vascular smooth muscle cell heme oxygenases generate guanylyl cyclase-stimulatory carbon monoxide. Circulation 91:2306-2309

22. Ewing JF, Maines MD 1991 Rapid induction of heme oxygenase-1 mRNA and protein by hyperthermia in rat brain: heme oxygenase- 2 is not a heat shock protein. Proc Natl Acad Sci USA 88:5364-5368

23. Verma A, Hirsch J, Glatt CE, Ronnett GV, Snyder SH 1993 Carbon monoxide: a putative neural messenger. Science 259:381-383

24. Krizbai IA, Deli MA, Pestenacz L, Siklos L, Szabo CA, Andras I, Joo F 1998 Expression of glutamate receptors on cultured cerebral endothelial cells. J Neurosci Res 54:814-819

25. Nathanson JA, Scavone C, Scanlon C, McKee M 1995 The cellular $\mathrm{Na}^{+}$pump as a site of action for carbon monoxide and glutamate; a mechanism for long-term modulation of cellular activity. Neuron 4:781-794

26. Chakder S, Rathi S, Ma XL, Rattan S 1996 Heme oxygenase inhibitor zinc protoporphyrin IX causes an activation of nitric oxide in the rabbit internal anal sphincter. J Pharmacol Exp Ther 277:1376-1382

27. McMillan K, Bredt DS, Hirsch DJ, Snyder SH, Clark JE, Masters BSS 1992 Cloned, expressed rat cerebellar NOS containing stoichiometric amounts of heme which binds CO. Proc Natl Acad Sci USA 89:11141-11145

28. Kozma F, Johnson RA, Nasjletti A 1997 Role of carbon monoxide in heme-induced dilation. Eur J Pharmacol 323:R1-R2

29. Wang R, Wang Z, Wu L 1997 Carbon monoxide-induced vasorelaxation and the underlying mechanisms. Br J Pharmacol 121:927-934

30. Balbanova L, Jaggar JH, Leffler CW 2001 Carbon monoxide (CO) is an endogenous activator of STOCs and $\mathrm{K}_{\mathrm{ca}}$ channels in cerebral artery smooth muscle cells. FASEB J 15:A125(abstr) 
31. Johnson RA, Lavesa M, DeSeyn K, Scholar MJ, Nasjletti A 1996 Heme oxygenase substrates acutely lower blood pressure in hypertensive rats. Am J Physiol 271:H1132-H1138

32. Colombari E, Bonagamba LG, Machado BH 1994 Mechanisms of pressor and bradycardic responses to L-glutamate microinjection into NTS of conscious rats. Am J Physiol 266:R730-R738

33. Johnson RA, Kozma F, Colombari E 1999 Carbon monoxide: from toxin to endogenous modulator of cardiovascular functions. Braz J Med Biol Res 32: $1-14$

34. Laitinen KSM, Salovarra K, Severgnini S, Laitinen JT 1997 Regulation of cyclic GMP levels in the rat frontal cortex in vivo: effects of exogenous carbon monoxide and phosphodiesterase inhibition. Brain Res 755:272278

35. Morishita S, Goto M, Fukkuda H 1986 Cerebellar cyclic nucleotides and the development of convulsion, with reference to the anticonvulsant activity of diazepam. Gen Pharmacol 17:343-346

36. Maines MD 2000 The heme oxygenase system and its functions in the brain. Cell Mol Biol 46):573-585

37. Chen K, Gunter K, Maines MD 2000 Neurons overexpressing heme oxygenase-1 resist oxidative stress mediated cell death. J Neurochem 75:304-313

38. Ewing JF, Maines MD 1993 Glutathione depletion induces heme oxygenase-1 (HSP32) mRNA and protein in rat brain. J Neurochem 60:1512-1519 